\title{
Minimum Loss Conditions in a Salient-Pole Wound-Field Synchronous Machine Drive
}

DOI:

10.1109/IECON.2019.8926793

\section{Document Version}

Accepted author manuscript

Link to publication record in Manchester Research Explorer

\section{Citation for published version (APA):}

Marques, G., \& lacchetti, M. (2019). Minimum Loss Conditions in a Salient-Pole Wound-Field Synchronous Machine Drive. In IECON 2019 - 45th Annual Conference of the IEEE Industrial Electronics Society

https://doi.org/10.1109/IECON.2019.8926793

\section{Published in:}

IECON 2019 - 45th Annual Conference of the IEEE Industrial Electronics Society

\section{Citing this paper}

Please note that where the full-text provided on Manchester Research Explorer is the Author Accepted Manuscript or Proof version this may differ from the final Published version. If citing, it is advised that you check and use the publisher's definitive version.

\section{General rights}

Copyright and moral rights for the publications made accessible in the Research Explorer are retained by the authors and/or other copyright owners and it is a condition of accessing publications that users recognise and abide by the legal requirements associated with these rights.

\section{Takedown policy}

If you believe that this document breaches copyright please refer to the University of Manchester's Takedown Procedures [http://man.ac.uk/04Y6Bo] or contact uml.scholarlycommunications@manchester.ac.uk providing relevant details, so we can investigate your claim.

\section{OPEN ACCESS}




\section{Minimum Loss Conditions in a Salient-Pole Wound-Field Synchronous Machine Drive}

\author{
Gil Marques \\ Department of Electrical and Computer Engineering \\ INESC-ID \\ Lisboa, Portugal \\ gil.marques@tecnico.ulisboa.pt
}

\author{
Matteo Felice Iacchetti \\ Department of Electrical Engineering \\ University of Manchester \\ Manchester, UK \\ matteo.iacchetti@manchester.ac.uk
}

\begin{abstract}
The conditions for minimum losses in a salientpole wound-field synchronous machine (WFSM) drive are studied in this paper. The drive comprises a WFSM energized by a stator inverter and excited by a dc-de converter both tied to a DC link. The minimum-loss operation is formulated as a nonlinear constrained optimization problem with equality constraints (e.g. torque command), and inequality constraints (flux, voltage and current limits). Lagrange multipliers are applied to solve this problem analytically. At low load, the torque demand can be met using different values for two independent electric variables (e.g. stator flux and field current magnitude). These can be optimized, thereby leading to two optimal implicit conditions. At higher load, when the stator flux reaches the maximum value, the free variables reduce to one and yield a single implicit optimal condition. For these two scenarios, the paper presents analytical derivations of the optimal conditions and numerical validation using MatLab. These conditions can be used to devise a control system optimizing the drive operation. ${ }^{1}$
\end{abstract}

Keywords-Synchronous machine drives, Optimization, Minimum loss conditions.

General

$i, I \quad$ Current (p.u.)

$\boldsymbol{L}_{\boldsymbol{d}}, \boldsymbol{L}_{\boldsymbol{q}} \quad$ Stator direct and quadrature inductance (p.u.).

$\boldsymbol{L}_{m} \quad$ Mutual inductance (p.u.)

$P \quad$ Active power (p.u.).

$\boldsymbol{T}_{L}, \boldsymbol{T}_{\boldsymbol{e}} \quad$ Load, Electromagnetic torque (p.u.).

$u \quad$ Voltage (p.u.).

$\boldsymbol{r}_{\boldsymbol{s}}, \boldsymbol{r}_{\boldsymbol{f}} \quad$ Stator and field resistances (p.u.).

$\lambda \quad$ Lagrange multiplier.

$\Delta U_{s} \quad$ Equivalent VSI voltage drop at rated current (p.u.).

$\Delta U_{f} \quad$ Equivalent dc/dc voltage drop at rated current (p.u.).

$\psi \quad$ Flux linkage (p.u.)

$\boldsymbol{\psi}_{\boldsymbol{M}} \quad$ Maximum stator flux linkage (p.u.).

$\boldsymbol{\omega}, \boldsymbol{\omega}_{m} \quad$ Mech. angular frequency/speed (p.u.).

\section{Superscripts}

* Reference value.

Subscripts

$d, q \quad$ Variables on rotor moving reference frame.

$N \quad$ Rated value.

\footnotetext{
1 This work was supported by national funds through FCT- Fundação para a Ciência e a Tecnologia with reference UID/CEC/50021/2019.
}

\section{INTRODUCTION}

In the last decades, the development of power electronics made possible running motor and generator drives at adjustable speed in order to meet the optimal operating conditions dictated by the load or prime-mover. In Vectorcontrolled ac machines, regardless to the specific reference flux, the supply current can be resolved into direct (in-phase with flux) and in-quadrature (torque-producing) components. The torque demand can be met by any combination of these two currents as long as the resulting flux and current are within the rated limits. Such as flexibility has been used to minimize losses in Permanent Magnet Synchronous Machines (PMSMs) since the mid 1980's [1]-[2], leading to the definition of optimal current trajectories for maximum torque per ampere or minimum losses [3]-[4]. A similar concept was applied to induction motors by either using search algorithms [5] or deriving the analytic expression for the optimal magnetizing current [6].

In multiport machines such as Wound-Field Synchronous Machines (WFSMs) and Doubly-Fed Induction Machines the stator/rotor magnetizing current split ratio offers a further degree of freedom for loss minimization. Analytical trajectories for the optimal current components for cylindrical WFSMs and DFIGs were derived in [7]-[8] and [9] respectively. More recently, the analysis was extended to cylindrical-WFSG [10] and DFIG rectifier-based [11] DC generation systems, considering the dc voltage or the stator frequency as an additional degree of freedom for the optimization. Optimal current trajectories for dual-VSI DFIG-DC systems were studied in [12] and [13].

Salient-pole WFSMs have been traditionally adopted as generators and are now receiving increasing attention for motoring applications especially in vehicle propulsion [14] because of their high efficiency when operating in deep fieldweakening region. To the best authors' knowledge, however, analytic optimal trajectories of stator and field currents for loss minimization are only available for cylindrical WFSMs [7] and they do not include converter losses.

This paper presents an optimization study of a salientpole WFSM drive and deduces analytical conditions for minimum-loss operation with given speed and torque demand. The study takes into account Joule, core and converter losses and considers two scenarios: 1), operation at low torque (i.e. well inside the flux, voltage and current capability domain), and 2), operation at maximum stator flux. At low torque levels, the optimal flux is below the rated value and the optimal d-, q-axis stator currents and field current are linked by two optimal conditions. For high torque levels, the flux is to be capped at rated value and the optimization returns a single optimal condition. The 
analytical conditions are validated using numerical optimization techniques.

The paper is structured as follows. Section II presents the layout of the system under study and the classic Park's model of the WFSM. This model already accounts for Joule losses, whereas core and converter losses are introduced separately in order to implement an algorithm for the minimization of total losses at an arbitrary operation point with given rotor speed and torque. The optimization problem is introduced in Section III. The analytical optimization using Lagrange multipliers is presented in section IV by deriving two sets of optimal conditions depending on the torque level. These results are verified using numerical methods in section V. Finally, section VI presents a control system based on the analytic optimal conditions in order to generate the reference currents that minimize the losses automatically.

\section{LAYOUT AND MODELING}

\section{A. Layout}

The considered system is presented in Fig. 1. The WFSM drive is tied to the DC power system using a Voltage Source Inverter (VSI) on the stator side and a dc/dc converter on the field winding. The rotor $\mathrm{dc} / \mathrm{dc}$ converter adjusts the field current while the VSI controls the stator currents in order to obtain the required torque $T_{e}$ at a given electrical speed $\omega_{m}$.

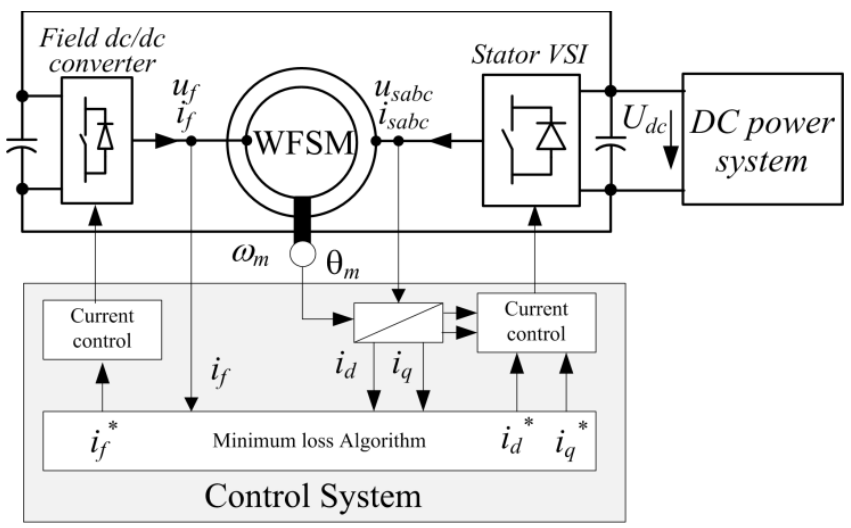

Fig. 1. Layout of the Wound field synchronous Machine Drive.

\section{B. Steady-state Park's model}

This paper focusses on the conditions for minimum losses at steady state. The classic Park's model of a synchronous machine in steady state is represented by the following equations in per-unit (p.u.), using motor convention and considering the rotor reference frame $d-q$ :

$$
\begin{gathered}
u_{d}=r_{s} i_{d}-\omega L_{q} i_{q} \\
u_{q}=r_{s} i_{q}+\omega\left(L_{d} i_{d}+L_{m} i_{f}\right) \\
u_{f}=r_{f} i_{f}
\end{gathered}
$$

The relations between flux linkages and currents are:

$$
\left[\begin{array}{l}
\psi_{d} \\
\psi_{q} \\
\psi_{f}
\end{array}\right]=\left[\begin{array}{ccc}
L_{d} & 0 & L_{m} \\
0 & L_{q} & 0 \\
L_{m} & 0 & L_{f}
\end{array}\right]\left[\begin{array}{l}
i_{d} \\
i_{q} \\
i_{f}
\end{array}\right]
$$

The torque in p.u. is given by:

$$
T_{e}=\psi_{d} i_{q}-\psi_{q} i_{d}=\left(L_{d}-L_{q}\right) i_{d} i_{q}+L_{m} i_{q} i_{f}
$$

\section{Losses in a WFSM drive}

The above described model accounts only for copper Joule losses.

$$
\text { Joule losses } \quad \mathrm{P}_{\mathrm{Js}}=r_{s} i_{d}^{2}+r_{s} i_{q}^{2}+r_{f} i_{f}^{2}
$$

Iron losses and VSI conducting losses must be included in the model in order to carry out the full optimization. This paper adopts a simplified representation for core, VSI and $\mathrm{dc} / \mathrm{dc}$ converter losses. These are added separately to the model, neglecting the effect on the relationship between currents, voltages, and torque, which are assumed to remain as in (1)-(4). Assuming a constant voltage-drop model for the semiconductors, and considering constant dc voltage and switching frequency, converter losses are roughly proportional to the current magnitude via coefficients $\Delta U_{S}$ and $\Delta U_{f}$, as outlined in (7)-(8).

$\begin{array}{ll}\text { Stator VSI losses } & P_{\text {inv } s}=\Delta U_{s} I_{s} \\ \text { Field dc/dc converter losses } & P_{d c_{-} d c}=\Delta U_{f} I_{f}\end{array}$

Hysteresis and eddy-current core losses in the stator at frequency $\omega$ are as follows

$$
\begin{gathered}
P_{s h}=P_{s h 0} \omega \psi^{2} \\
P_{e h}=P_{e h 0} \omega^{2} \psi^{2}
\end{gathered}
$$

Excess and rotor core losses are ignored so the total core losses are

$$
P_{f e}=P_{s h 0} \omega \psi^{2}+P_{e h 0} \omega^{2} \psi^{2}=\psi^{2} f(\omega)
$$

\section{Formulation OF THE OPTIMIZATION PROBLEM}

This paper aims at finding the optimal control variables which minimize losses for a given p.u. speed $\omega$ and torque $T_{e}$. The objective function is the expression of total losses:

$$
W=\psi^{2} f(\omega)+r_{s} i_{d}^{2}+r_{s} i_{q}^{2}+r_{f} i_{f}^{2}+\Delta U_{s} I_{s}+\Delta U_{f} I_{f}
$$

The optimization procedure considers the following operational constraints in addition to (4):

\section{1) Equality constraints:}

$$
T_{L}=T_{e}=\psi_{d} i_{q}-\psi_{q} i_{d}
$$

2) Inequality constraints:

$$
\begin{gathered}
I_{s}=\sqrt{i_{d}^{2}+i_{q}^{2}} \leq I_{s N} \\
I_{f} \leq I_{f N} \\
U_{s}=\sqrt{u_{d}^{2}+u_{q}^{2}} \leq U_{s N} \\
\psi=\sqrt{\psi_{d}^{2}+\psi_{q}^{2}} \leq \psi_{M}
\end{gathered}
$$


The resulting optimization problem can be solved using either analytical or numerical methods. In section IV the method of Lagrange multipliers is used to obtain simplified expressions for the optimal conditions. They are used for the control of the machine. In section $\mathrm{V}$, Matlab numerical methods are used to validate the simplified results.

\section{ANALYTICAL OPTIMIZATION}

\section{A. Unconstrained Optimization by Lagrange Multipliers}

When current, voltage and flux are within their limits, the appropriate Lagrange function is:

$$
\begin{gathered}
W_{L}=\left(\psi_{d}^{2}+\psi_{q}^{2}\right) f(\omega)+r_{s} i_{d}^{2}+r_{s} i_{q}^{2}+r_{f} i_{f}^{2}+ \\
\Delta U_{s} \sqrt{i_{d}^{2}+i_{q}^{2}}+\Delta U_{f} I_{f}-\lambda\left(T_{L}-\psi_{d} i_{q}+\psi_{q} i_{d}\right)
\end{gathered}
$$

By using (4), the fluxes can be eliminated and (18) is reformulated as follows

$$
\begin{aligned}
& W_{L}=\left(\left(L_{d} i_{d}+L_{m} i_{f}\right)^{2}+\left(L_{q} i_{q}\right)^{2}\right) f(\omega)+r_{s} i_{d}^{2}+r_{s} i_{q}^{2}+ \\
& r_{f} i_{f}^{2}+\Delta U_{s} \sqrt{i_{d}^{2}+i_{q}^{2}}+\Delta U_{f} I_{f}-\lambda\left(T_{L}-\left(L_{d} i_{d}+L_{m} i_{f}\right) i_{q}+\right. \\
& \left.L_{q} i_{q} i_{d}\right)
\end{aligned}
$$

which contains three residual electric variables $\left\{i_{d}, i_{q}, i_{f}\right\}$ and two inputs $\left\{\omega, T_{L}\right\}$. The optimality conditions follows from the partial derivatives of (19) with respect to $\left\{i_{d}, i_{q}, i_{f}\right\}$

$$
\begin{aligned}
& \frac{\partial W_{L}}{\partial i_{d}}=2 r_{s} i_{d}+\frac{\Delta U_{s} i_{d}}{\sqrt{i_{d}^{2}+i_{q}^{2}}}+\left(L_{d}-L_{q}\right) i_{q} \lambda+2 L_{d}\left(L_{d} i_{d}+\right. \\
& \left.L_{m} i_{f}\right) f(\omega)=0 \\
& \frac{\partial W_{L}}{\partial i_{q}}=2 r_{s} i_{q}+\frac{\Delta U_{s} i_{q}}{\sqrt{i_{d}^{2}+i_{q}^{2}}}+\left(L_{d}-L_{q}\right) i_{d} \lambda+L_{m} i_{f} \lambda+2 L_{q}^{2} i_{q} f(\omega)=0
\end{aligned}
$$

$\frac{\partial W_{L}}{\partial i_{f}}=2 r_{f} i_{f}+\Delta U_{f}+L_{m} i_{q} \lambda+2 L_{m}\left(L_{d} i_{d}+L_{m} i_{f}\right) f(\omega)=0$

Due to the remaining equality constraint (13), there are only two free variables among $\left\{i_{d}, i_{q}, i_{f}\right\}$, so two optimal conditions are expected.

\section{1) First optimal condition}

Solving (22) with respect to multiplier $\lambda$ gives

$$
\lambda=-\frac{2 r_{f} i_{f}+\Delta U_{f}+2 L_{m}\left(L_{d} i_{d}+L_{m} i_{f}\right) f(\omega)}{L_{m} i_{q}}
$$

Replacing (23) into (20) and rearranging yields

$$
2 r_{s} i_{d}+\frac{\Delta U_{s} i_{d}}{\sqrt{i_{d}^{2}+i_{q}^{2}}}+2 f(\omega) L_{q}\left(L_{d} i_{d}+L_{m} i_{f}\right)=\frac{\left(L_{d}-L_{q}\right)}{L_{m}}\left(2 r_{f} i_{f}+\right.
$$$$
\left.\Delta U_{f}\right)
$$

which can be rewritten as

$$
2 r_{s} i_{d}+\frac{\Delta U_{s} i_{d}}{\sqrt{i_{d}^{2}+i_{q}^{2}}}+2 f(\omega) \psi_{d} L_{q}=\frac{\left(L_{d}-L_{q}\right)}{L_{m}}\left(2 r_{f} i_{f}+\Delta U_{f}\right)
$$

Equation (24) or (25) represent the optimal relationship between voltage drops on the $d$-axis and excitation and contain a saliency-related term.

\section{2) Second optimal condition}

By using (25) and (4), multiplier $\lambda$ in (23) can be rewritten in the form

$$
\lambda=-\frac{1}{\left(L_{d}-L_{q}\right) i_{q}}\left(2 r_{s} i_{d}+\frac{\Delta U_{s} i_{d}}{\sqrt{i_{d}^{2}+i_{q}^{2}}}+2 f(\omega) \psi_{d} L_{q}\right)-\frac{2 f(\omega) \psi_{d}}{i_{q}}
$$

By replacing the first $\lambda$ in (21) with (26) - i.e. in factor $\left(L_{d}-L_{q}\right) i_{d} \lambda$ - and the second $\lambda$ with $(23)$ - i.e. in factor $L_{m} i_{f} \lambda$ - and rearranging gives

$$
\begin{array}{r}
2 r_{s} i_{d}^{2}+\frac{\Delta U_{s} i_{d}^{2}}{\sqrt{i_{d}^{2}+i_{q}^{2}}}+2 r_{f} i_{f}^{2}+\Delta U_{f} i_{f}+2 f(\omega) \psi_{d}^{2}=2 r_{s} i_{q}^{2}+\frac{\Delta U_{s} i_{q}^{2}}{\sqrt{i_{d}^{2}+i_{q}^{2}}}+ \\
2 f(\omega) \psi_{q}^{2}
\end{array}
$$

The right-hand side of equality (27) contains only losses associated with magnetizing terms (d-axis). Conversely, the left-hand side contains only losses associated with the q-axis are present. Apart from factor " 2 " weighting Joule losses, (27) can be interpreted as " $d$-axis losses $=q$-axis losses" and may be called "dq-axis loss matching condition".

\section{B. Flux constrained optimization}

The optimal stator flux increases with torque. When stator flux reaches the limit, the maximum-flux constraint applies, turning inequality constraint (17) into an equality constraint. The resulting Lagrange function is:

$$
\begin{gathered}
W_{L \psi}=r_{s} i_{d}^{2}+r_{s} i_{q}^{2}+\Delta U_{s} \sqrt{i_{d}^{2}+i_{q}^{2}}+r_{f} i_{f}^{2}+\Delta U_{f} I_{f}- \\
\lambda_{1 \psi}\left(T_{L}-\left(L_{d}-L_{q}\right) i_{d} i_{q}-L_{m} i_{f} i_{q}\right)-\lambda_{2 \psi}\left(\psi_{M}^{2}-\right. \\
\left.\left(L_{d}^{2} i_{d}^{2}+L_{m}^{2} i_{f}^{2}+2 L_{d} L_{m} i_{d} i_{f}\right)-L_{q}^{2} i_{q}^{2}\right)
\end{gathered}
$$

where subscript " $\psi$ " denotes that the optimization problem is different from the one in previous Section IV-A. The new optimality conditions are:

$$
\begin{aligned}
& \frac{\partial W_{L \psi}}{\partial i_{d}}=2 r_{s} i_{d}+\frac{\Delta U_{s} i_{d}}{\sqrt{i_{d}^{2}+i_{q}^{2}}}+\lambda_{1 \psi}\left(L_{d}-L_{q}\right) i_{q}+\lambda_{2 \psi}\left(2 L_{d}^{2} i_{d}+\right. \\
& \left.2 L_{d} L_{m} i_{f}\right)=0 \\
& \quad \frac{\partial W_{L \psi}}{\partial i_{q}}=2 r_{s} i_{q}+\frac{\Delta U_{s} i_{q}}{\sqrt{i_{d}^{2}+i_{q}^{2}}}+\lambda_{1 \psi}\left(L_{d}-L_{q}\right) i_{d}+\lambda_{1 \psi} L_{m} i_{f}+ \\
& \lambda_{2 \psi}\left(2 L_{q}^{2} i_{q}\right)=0 \\
& \frac{\partial W_{L \psi}}{\partial i_{f}}=2 r_{f} i_{f}+\Delta U_{f}+\lambda_{1 \psi} L_{m} i_{q}+\lambda_{2 \psi}\left(2 L_{m}^{2} i_{f}+\right. \\
& \left.2 L_{d} L_{m} i_{d}\right)=0
\end{aligned}
$$

Considering (4) and (31)

$$
\lambda_{1 \psi} i_{q}=-\frac{2 r_{f} i_{f}+\Delta U_{f}}{L_{m}}-\lambda_{2 \psi} 2 \psi_{d}
$$

After some algebraic manipulations, the second Lagrange multiplier is: 


$$
\lambda_{2 \psi}=-\frac{r_{s} i_{d}^{2}+\frac{\Delta U_{s} i_{d}^{2}}{\sqrt{i_{d}^{2}+i_{q}^{2}}}+r_{f} i_{f}^{2}+\frac{\Delta U_{f}}{2} i_{f}-r_{s} i_{q}^{2}-\frac{\Delta U_{s} i_{q}^{2}}{\sqrt{i_{d}^{2}+i_{q}^{2}}}}{\psi_{d}^{2}-\psi_{q}^{2}}
$$

Multiplying (29) and (30) by $i_{d}$ and $i_{q}$ respectively, summing the resulting equations and using (32) yield:

$$
2 r_{s} I_{s}^{2}+\Delta U_{s} I_{s}+2 r_{f} i_{f}^{2}+\Delta U_{f} i_{f}+2 \lambda_{1 \psi} T_{e}+2 \lambda_{2 \psi} \psi_{M}^{2}=0
$$

Equation (34) gives the condition for minimum losses at constant (rated) flux, which is now only one condition since there are two functions to impose, the torque and the flux. Once again, the Joule losses appear multiplied by factor 2 when compared to converter losses. According to (34), the rotor speed has no influence on the optimal condition. Thus, the optimal values of currents depend only on torque. Using (34) and (4), (13) and (17) - along with (32)-(33) to eliminate multipliers $\lambda_{1 \psi}$ and $\lambda_{2 \psi}-$, it is possible to generate the optimal variables $\left\{i_{d}, i_{q}, i_{f}\right\}$ numerically as a function of torque, as shown in Fig 2 for the considered $1750 \mathrm{kVA}$ WFSM. Current component $i_{d}$ is well approximated by a quadratic polynomial. This approximation will be used to devise a WFSM control system handling the operation at high torque under maximum-flux condition.

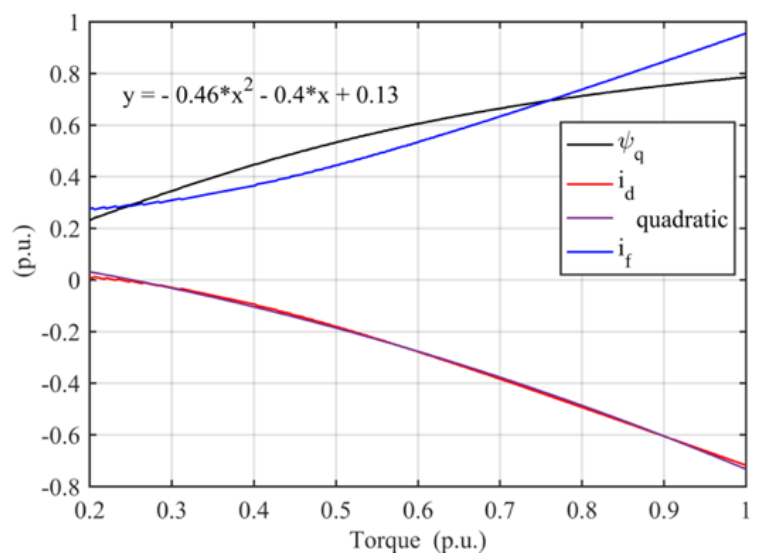

Fig. 2. Optimal variables versus torque at maximum flux.

\section{Numerical Optimization Results}

The results from the numerical optimization were obtained using Matlab optimization package. For a comprehensive assessment of the analytical conditions obtained in Section IV, the numerical optimization results include also a small range of rotor speeds where stator voltage limits are hit.

Results are presented in Fig. 3 to Fig. 10: they refer to a $1750 \mathrm{kVA}$ salient-pole WFSM with the parameters in the Appendix.

The stator flux is presented in Fig. 3 showing that the maximum (rated) flux should be used in the majority of plane $\left(\omega_{m}, T_{e}\right)$. The stator voltage is presented in Fig. 4. Three regions are shown, including the maximum voltage condition, not studied analytically in this paper.

The d- and q- stator current components are presented in Fig. 5 and Fig. 6, and the field current is presented in Fig. 7. In generating operation, the q-axis current is negative so the optimal $i_{q}$ would be mirrored on the $\left(\omega_{m}, T_{e}\right)$ plane, whereas the other optimal surfaces remain the same.

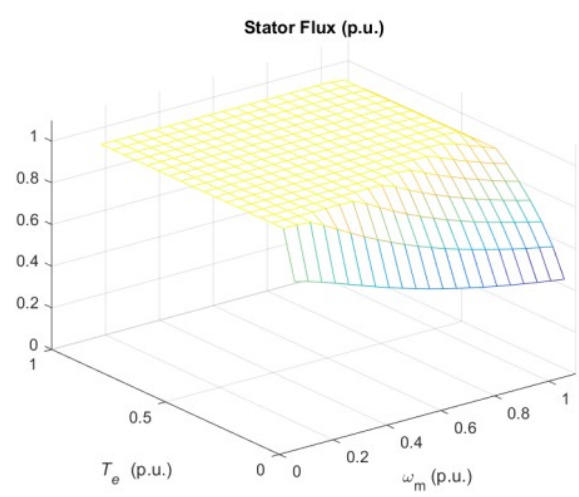

Fig. 3. Optimal stator flux

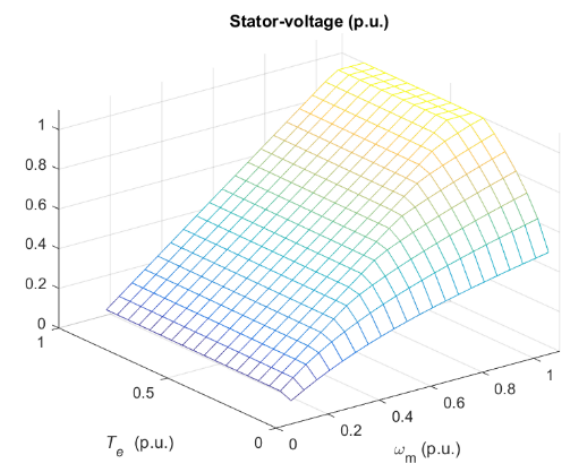

Fig. 4. Optimal stator voltage.

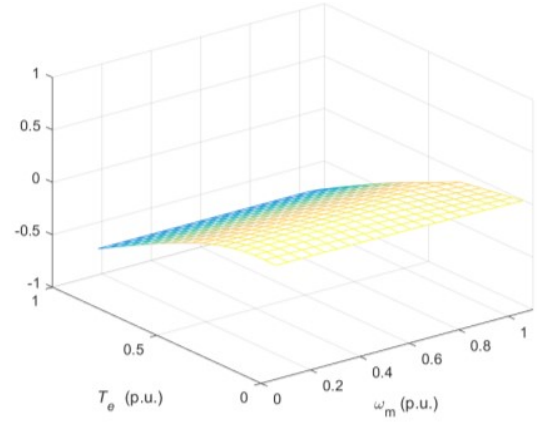

Fig. 5. Stator d- current component.

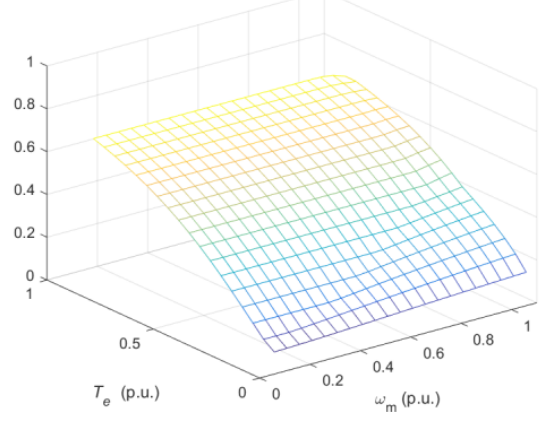

Fig. 6. Stator q-axis current component.

Optimal conditions (25), (27), and (34) are verified in Fig. 8, Fig. 9 and Fig. 10 respectively. In particular, Fig. 8 and Fig. 9 show the difference between the left-hand and right-hand sides of (25) and (27), so they are zero in the regions where (25) and (27) are valid, i.e. when the stator flux is below the rated value. 


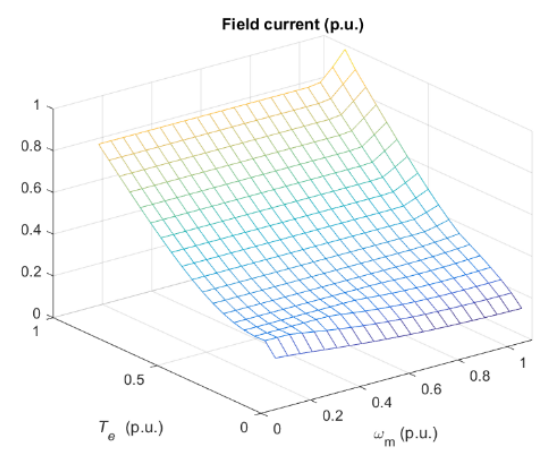

Fig. 7. Field current.

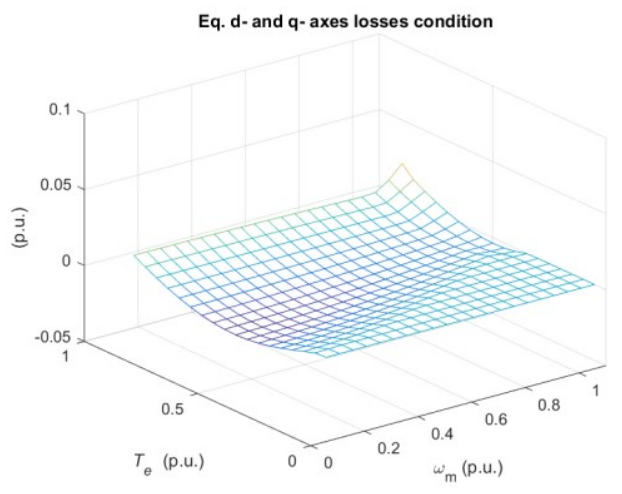

Fig. 8. Equality of d- and q-axes Losses obtained from the optimization.

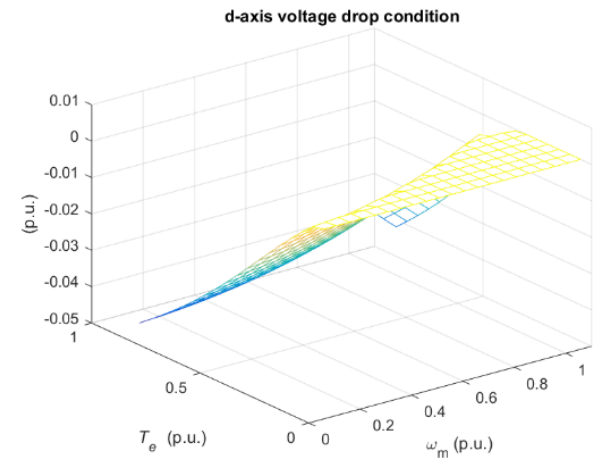

Fig. 9. D-axis voltage drop condition.

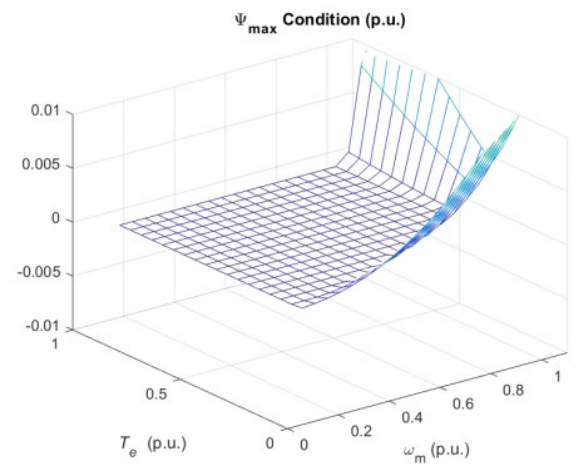

Fig. 10. Constrained flux condition.

As mentioned in Section IV, it can be verified that the speed has no influence on the optimal state variables in the maximum-flux region.

\section{CONTROL SYSTEM AND RESUlTS}

Using the concepts described in Section IV, a control system is proposed enforcing optimal conditions (25) and (27) or (34), depending on the operating region. Three cases are studied. In the first case the torque is small and consequently the flux can be automatically adjusted depending on torque and speed levels. In the second case the torque is higher and so the flux is capped at its maximum value. The transition between these two different conditions is studied in the third case. The schematic of the control system handling these three cases is presented in Fig. 11.

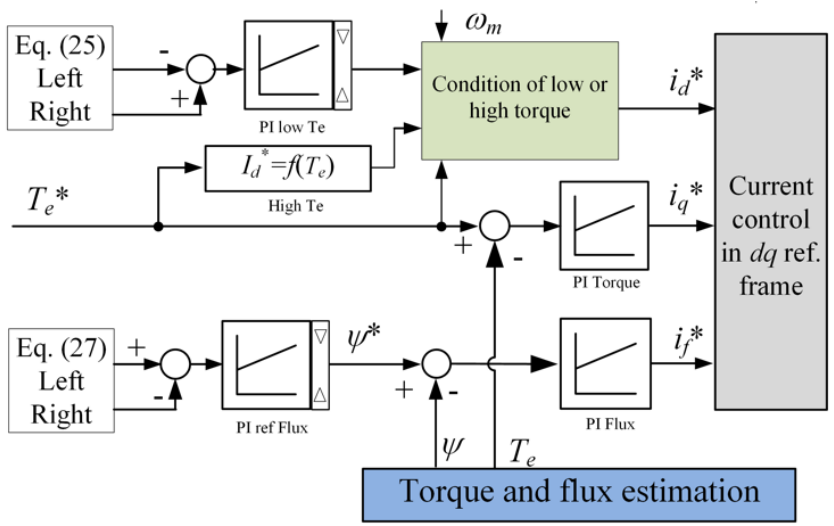

Fig. 11. Control system for adjustable flux region.

The WFSM is operated using current control implemented in the $d q$ rotor reference frame. This needs torque and flux estimation. The three reference values $\left\{i_{d}^{*}, i_{q}^{*}, i_{f}^{*}\right\}$ for the WFSM currents are obtained as follows.

The field current reference $i_{f}^{*}$ controls the flux level and is set by the Proportional Integral (PI) controller "PI Flux", see Fig. 11. The reference command of this controller comes from the "PI ref Flux" controller whose output is limited at maximum reference flux $\psi_{M}$. This controller enforces optimal condition (27) as shown in Fig. 11, as long as the reference flux is lower than $\psi_{M}$. In flux saturation regimen, (27) is no longer used. The saturation is implemented directly at the output of the PI controller.

The in-quadrature current component $i_{q}$ is used to control the torque so its reference value is set by torque controller "PI-torque".

The reference command $i_{d}^{*}$ for the direct current component depends on the operating point and is calculated by two different blocks, depending on low- or high-torque operation. In the first scenario (low torque), $i_{d}^{*}$ is set by a third PI controller (PI-low- $\mathrm{T}_{\mathrm{e}}$ ) enforcing optimal condition (25), similarly to what done for (27). For high torque values, $i_{d}^{*}$ is set from a parabolic approximation of the unique optimal condition implicitly defined by (34)-(32) as a function of the torque demand and as shown in Fig. 2.

\section{A. Unconstrained flux control}

For low level torque, where adjustable flux should be used, the minimum conditions (25) and (27) are been used. Since it is difficult to obtain the reference variables in an explicit form, here it is proposed to use PI controllers to solve those equations as shown in Fig. 11. Since the torque is proportional to $i_{q}$, this variable is used to control the torque and is the output of a classical PI controller. Currents $i_{d}$ and $i_{f}$ are used to optimize the system.

Fig. 12 shows a simulation result when ascending and descending ramps of torque reference is applied. In this case 
the flux is always adjusted and (25)-(27) are always verified.
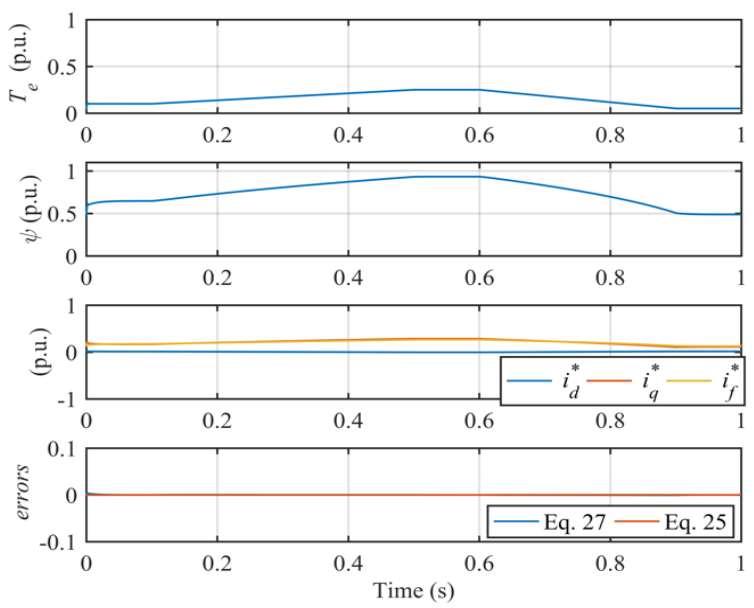

Fig. 12. Results obtained in the adjustable flux region for ramps of reference torque.

\section{B. Control at maximum flux}

Fig. 13 shows the flux and current variables obtained when ascending and descending torque ramps are imposed, with a minimum torque above the threshold triggering the high-torque operating mode. The saturation for stator flux is set at 1 p.u. and the reference currents have a behavior similar to that in the previous simulation. However, conditions (25) and (27) are now violated, as shown in the subplot at the bottom of Fig. 13.
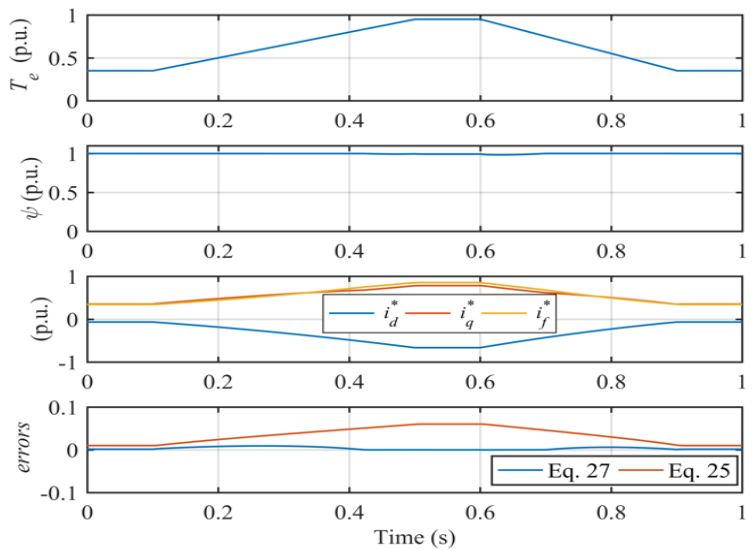

Fig. 13. Results obtained in the maximum flux region.

\section{Transition between the two regions}

The transition between both regions is shown in Fig. 14 The reference torque increases from a very low value until 0.9 p.u.. The transition occurs at $\mathrm{t}=300 \mathrm{~ms}$ and $\mathrm{t}=1.1 \mathrm{~s}$ approximately and is smooth, without considerable discontinuities.

\section{CONCLUSION}

The conditions for minimum-loss operation in a salientpole WFSM drive connected to a dc network were discussed in this paper. The optimal conditions were obtained analytically using Lagrange multipliers and were verified with a numerical optimization package. A control scheme for minimum-loss operation based on the analytic optimal conditions was presented. To that purpose, the implicit optimal conditions are enforced using two PI controllers returning the $d$-axis and field reference currents to be imposed by vector control. The results obtained in this paper can be used for practical implementation of the control.

\section{APPENDIX}

Per-unit parameters of the WFSM and VSIs used in the study: $r_{\mathrm{s}}=0.0083, r_{\mathrm{f}}=0.004, L_{\mathrm{m}}=3.4, L_{\mathrm{d}}=3.66, L_{\mathrm{q}}=1.12$, $\Delta U_{\mathrm{s}}=0.04, P_{\mathrm{fe} 0}=0.01, \Delta U_{\mathrm{f}}=0.01$.
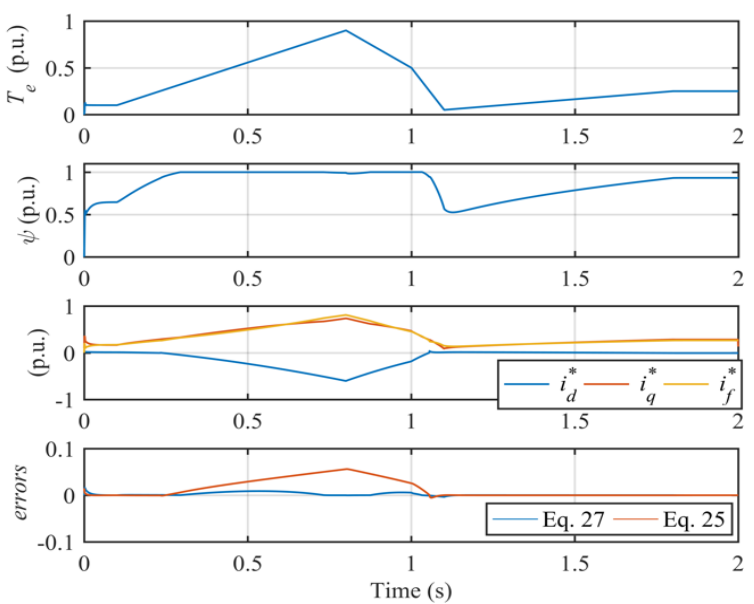

Fig. 14. Transition between low- and high-torque operating regions.

\section{REFERENCES}

[1] R. S. Colby and D. W. Novotny, "An efficiency-optimizing permanent- magnet synchronous motor drive," IEEE Trans. Ind. Appl., vol. 24, no. 3, May/Jun. 1988, pp. 462-469.

[2] Jiunn-Jiang Chen, Kan-Ping Chin , "Minimum Copper Loss FluxWeakening Control of Surface Mounted Permanent Magnet Synchronous Motors," IEEE Trans. Pow. Electr., vol. 18, no. 4, July 2003, pp. 929-936.

[3] Yu-seok Jeong, Seung-Ki Sul, Silva Hiti, Khwaja M. Rahman, "Online Minimum-Copper-Lass Control of an Interior PermanentMagnet Synchronous Machine for Automotive Applications," IEEE Trans Ind. App., vol. 42, no. 5, Sept/Oct 2006, pp. 1222-1229.

[4] D. S. Kirschen, D. W. Novotny and T. A. Lipo, "On-Line Efficiency Optimization of a Variable Frequency Induction Motor Drive," IEEE Trans. Ind. Appl., vol. IA-21, no. 3, pp. 610-616, May 1985.

[5] G. O. Garcia, J. C. M. Luis, R. M. Stephan and E. H. Watanabe, "An efficient controller for an adjustable speed induction motor drive," IEEE Trans. Ind. Electron, vol. 41, no. 5, pp. 533-539, Oct. 1994.

[6] M. N. Uddinand, S. W. Nam, "Newonlineloss-minimization-based control of an induction motor drive," IEEE Trans. Power Electron., vol. 23, no. 2, pp. 926-933, Mar. 2008

[7] C. Mademlis, J. Xypteras, and N. Margaris, "Loss Minimization in Wound-Field Cylindrical Rotor Synchronous Motor Drives," IEEE Trans. Power Electron., vol. 13, no. 2, March 1998 , pp. 288-296.

[8] C. Mademlis, N. Margaris, J. Xypteras, "Magnetic and Thermal Performance of a Synchronous Motor Under Loss Minimization Control," IEEE Trans. En. Conv., vol. 15, no. 2, 2000, pp. 135-142.

[9] Yifan Tang, Longya Xu, "A flexible active and reactive power control strategy for a variable speed constant frequency generating system," IEEE Trans. Power Electron., vol. 10, no. 4, pp. 472-478, Jul. 1995.

[10] M. F. Iacchetti, G. D. Marques, J. Apsley and S. Djurovic, "Minimum-loss operation of a variable-speed wound-field synchronous generator," 8th IET Int. Conf. on Pow. Electron., Mach. and Driv. (PEMD 2016), Glasgow, 2016, pp. 1-6.

[11] S. M. A. Cruz, G. D. Marques, P. F. C. Gonçalves and M. F. Iacchetti, "Predictive Torque and Rotor Flux Control of a DFIG-DC System for Torque Ripple Compensation and Loss Minimization," IEEE Trans. Ind. Electron, vol. 65, no. 12, pp. 9301-9310, Dec. 2018.

[12] S. Yan, A. Zhang, H. Zhang, J. Wang, B. Cai, "Optimized and coordinated model predictive control sheme for DFIGs with DCBased converter system," J. Mod. Pow. Syst. Clean En., 5: 620, 2017.

[13] Y. Han, J. I. Ha, "Control Method of Double Inverter Fed Wound Machine for Minimizing Copper Loss in Maximized Operating Area," IEEE Trans. Ind. Electron., vol. 64, n. 10, pp. 7700-7710, Oct. 2017.

[14] https://www.speakev.com/threads/renault-reveals-new-air-cooledcompact-ev-motor.5403/. 